\title{
The effect of minimum dwell cycles on the environmental and fatigue response of RR1000
}

\author{
J.H. O’Hanlon ${ }^{1, \text { a }}$, M.C. Hardy ${ }^{2}$, D.J. Child ${ }^{2}$, B. Foss ${ }^{3}$, P.J. Withers ${ }^{4}$, and M.R. Bache ${ }^{1}$ \\ ${ }^{1}$ Materials Research Centre, School of Engineering, Swansea University, Singleton Park, Swansea, SA2 8PP, UK \\ ${ }^{2}$ Rolls-Royce plc, PO Box 31, Derby, DE24 8BJ, UK \\ ${ }^{3}$ Department of Materials, Royal School of Mines, Imperial College, Prince Consort Road, London, SW7 2AZ, UK \\ ${ }^{4}$ School of Materials, University of Manchester, Grosvenor St, Manchester, M13 9PL, UK
}

\begin{abstract}
Minimum dwell fatigue testing of nickel based superalloy FG RR 1000 at $650^{\circ} \mathrm{C}$ has led to significant reductions in fatigue life. The reduction in fatigue life under minimum dwell fatigue has been caused by relatively early and multiple crack initiation events from a highly oxidised surface. The depth of oxidation damage, in the present circumstances achieved under cyclic loading at $650^{\circ} \mathrm{C}$, appeared similar to previous stress free isothermal exposure studies conducted on RR1000 but at higher temperature/shorter duration suggesting an enhancement in oxidation due to applied stress. Surface oxidation and crack initiation were clearly resisted under the baseline loading cycle despite being exposed for similar periods of exposure time. To understand the respective effects of the environment and minimum dwell period, vacuum fatigue and hold time oxidation tests have been completed.
\end{abstract}

\section{Introduction}

Fatigue endurance behaviour from dwell periods at maximum load or strain (referred to here as maximum dwell fatigue) has been widely reported in the past but recent work investigating minimum dwell fatigue, i.e. a dwell period imposed at minimum load or strain, has received increasing interest due to its comparison to out-of-phase thermo-mechanical fatigue (OOP TMF) cycling. Bache [1], Gabb [2] and Telesman [3] and their respective co-workers, have reported large reductions in fatigue life under minimum dwell fatigue in contrast to maximum dwell and baseline fatigue cycling, along with high levels of environmental interaction at temperatures between $650{ }^{\circ} \mathrm{C}$ and $704^{\circ} \mathrm{C}$.

This paper will report the effect of minimum dwell fatigue on the environmental and fatigue response of the nickel-based superalloy RR1000 at $650{ }^{\circ} \mathrm{C}$. Crack initiation and growth under minimum dwell conditions will be discussed considering surface and subsurface oxidation damage. A study of oxidation damage during the minimum dwell period by using a compressive stress hold time is also reported.

\section{Experimental methods}

\subsection{Specimen preparation}

The nickel disc alloy RR1000 has a nominal composition of $18.5 \mathrm{Co}, 15 \mathrm{Cr}, 5 \mathrm{Mo}, 3.6 \mathrm{Ti}, 3 \mathrm{Al}, 2 \mathrm{Ta}, 0.5 \mathrm{Hf}, 0.06 \mathrm{Zr}$, $0.027 \mathrm{C}, 0.015 \mathrm{~B}$, bal $\mathrm{Ni}$ (wt.\%). Plain round bar test pieces, of $6.4 \mathrm{~mm}$ diameter $14 \mathrm{~mm}$ gauge length, were machined from heat treated isothermal forgings produced

\footnotetext{
${ }^{a}$ Corresponding author: $482567 @$ swansea. ac.uk
}

by ATI Ladish Forgings and provided by Rolls-Royce plc. The starting material had an average grain size of 4-8 $\mu \mathrm{m}$ with a $47 \% \gamma^{\prime}$ volume fraction [4], All test pieces were low stress ground and longitudinally polished to produce a high quality surface finish $\left(\mathrm{R}_{a}<0.25 \mu \mathrm{m}\right)$ to minimise surface initiating features and to minimise residual stresses. Surface analyses were performed on each specimen batch to ensure adherence to the surface finish specification. A compressive residual stress of $-380 \mathrm{MPa}$ was recorded at the surface of a pre-tested specimen by $\mathrm{X}$-ray diffraction.

\subsection{Baseline and minimum dwell fatigue}

Fatigue tests were performed under load and strain control using closed loop servo-hydraulic test rigs at Swansea University and Swansea Materials Research and Testing Ltd (SMaRT). Strain control tests were performed at $0.7 \%$ $\Delta \varepsilon$ using a strain ratio $\mathrm{R}$ of 0 and a strain rate of $0.5 \% \mathrm{~s}^{-1}$. Load control tests were performed using the stabilised stress limits obtained from a strain control test conducted at $0.9 \% \Delta \varepsilon(0.25 \mathrm{~Hz})$.

Minimum dwell fatigue tests were performed with a 30 second dwell period imposed at minimum load/strain (1-1-1-30) to induce failure at $650^{\circ} \mathrm{C}$ (Fig. 1a). Baseline fatigue (1-1-1-1) tests under strain control were cycled for at least 24 hours; the stress limits recorded, and then cycled to failure under load control using the stabilised stress levels. The strain levels were monitored during load control fatigue using extensometers to assess any strain accumulation.

Minimum dwell tests were repeated under a hard vacuum $\left(\sim 10^{-5}\right.$ torr $)$ to understand the environmental effects, demonstrated by Bache et al. [1] during previous

This is an Open Access article distributed under the terms of the Creative Commons Attribution License 4.0, which permits unrestricted use, distribution, and reproduction in any medium, provided the original work is properly cited. 

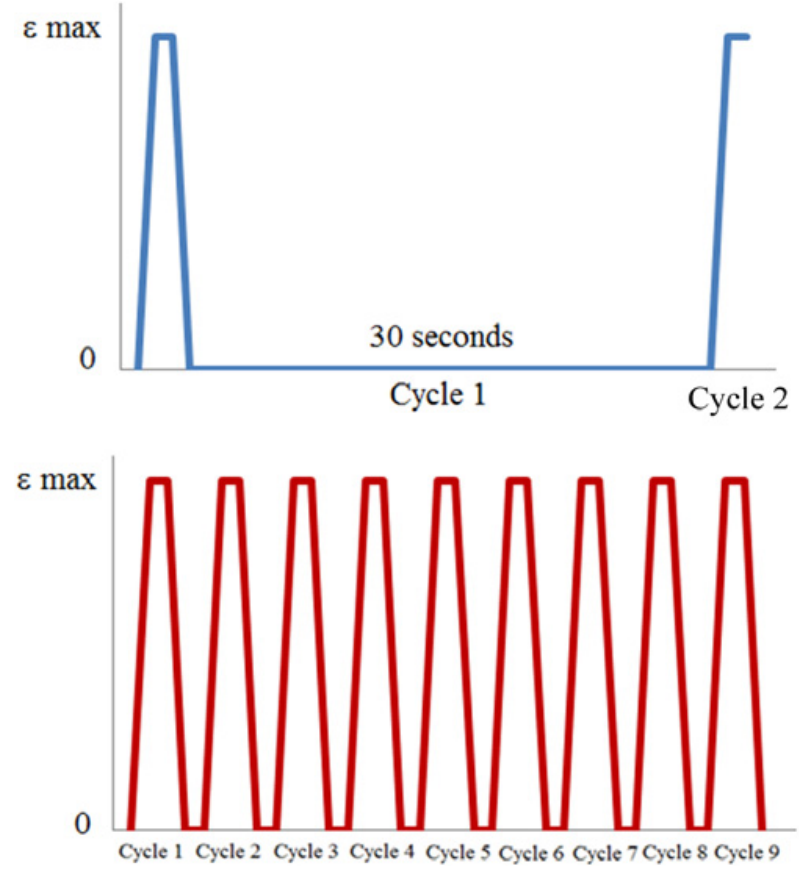

Figure 1. The (a) 30 second minimum dwell (1-1-1-30) and (b) baseline (1-1-1-1) fatigue waveforms used under strain control.

air fatigue tests. Vacuum fatigue testing was performed using a closed loop servo-hydraulic test rig using the same stress levels determined in $0.9 \% \Delta \varepsilon$ testing.

Fractured test pieces were cleaned using kerosene in an ultrasonic bath before repeating with acetone. Fracture surfaces were viewed using a field emission gun scanning electron microscope (FEG SEM) to identify the origin of fatigue crack nucleation.

\subsection{Hold time oxidation}

The principal difference between the baseline and minimum dwell fatigue tests is the addition of a 30 second hold period at the minimum stress/strain (Fig. 1). A series of thermal exposures were designed to examine the effect of the dwell period on the enhanced environmental response reported by references [1-3]. The stresses generated during strain control testing indicate that test pieces are subjected to a compressive stress during the minimum dwell period. Thermal exposure under a compressive stress was performed in an effort to replicate the enhanced oxidation levels found in minimum dwell test pieces.

Cylindrical test pieces ( $4.5 \mathrm{~mm}$ diameter, $6 \mathrm{~mm}$ length) were machined, using low stress grinding, from RR1000 material to an average surface roughness $\mathrm{R}_{a}<0.25 \mu \mathrm{m}$. Test pieces were placed between two flat platens and held under stresses of $-300 \mathrm{MPa}$ and $-600 \mathrm{MPa}$ each at $650^{\circ} \mathrm{C}$ and $700^{\circ} \mathrm{C}$ for 200 hours using an electric screw test rig. The scale and subsurface oxidation damage were then studied by cross-sectional preparation and analysis using a FEG SEM.

Accumulation of oxidation damage under compression was compared with that from sustained tensile loading

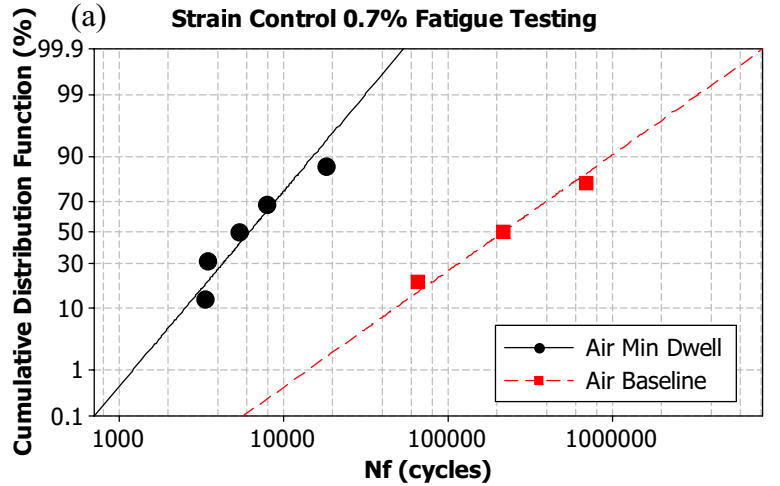

(b)

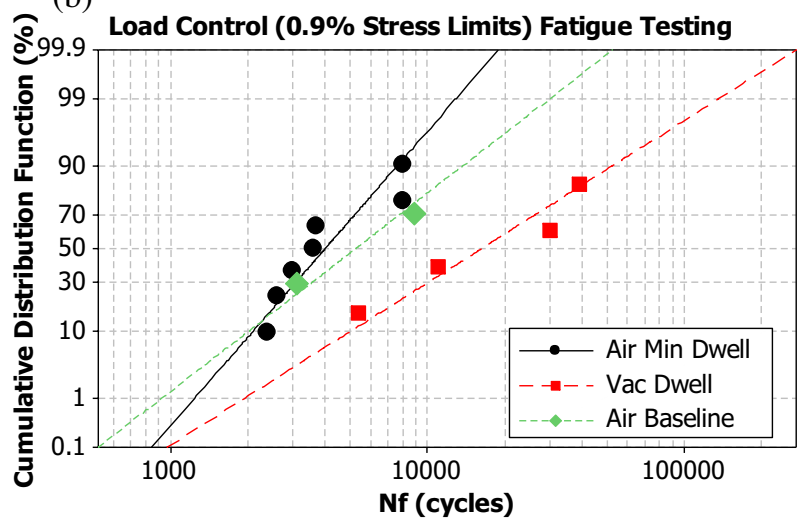

Figure 2. Cumulative distribution function (CDF) of (a) strain and (b) load control endurance data.

and stress free thermal exposures. Two $650{ }^{\circ} \mathrm{C}$ and two $700{ }^{\circ} \mathrm{C}$ furnace tests were completed, and compared with thermal exposures under compressive stresses and a 200 hour $700{ }^{\circ} \mathrm{C}$ tensile creep test at $600 \mathrm{MPa}$.

\subsection{Oxidation preparation and analysis}

Creep, stress free and fatigue test pieces required careful preparation for oxidation studies in the FEG SEM. In order to protect the delicate oxidation damage, a thin gold sputtered layer was applied to the surface of oxidised test pieces. Samples were then plated using a 'bright nickel' plate solution $\left(\mathrm{NiSO}_{4}+\mathrm{H}_{3} \mathrm{BO}_{3}+\mathrm{NiCl}_{2}\right)$ at approximately $50{ }^{\circ} \mathrm{C}$ for at least 30 minutes before being mounted in conductive mount and prepared by $\mathrm{SiC}$ paper, diamond polishing and colloidal Si $(0.06 \mu \mathrm{m})$. All specimens were studied in the polished condition.

The average oxide scale and internal damage measurements were obtained from 10 oxide images, with 5 equi-distant measurements taken from each.

\section{Results}

\subsection{Fatigue results}

The results of minimum dwell and baseline fatigue tests on RR1000 at $650{ }^{\circ} \mathrm{C}$ are shown in Fig. 2. Strain control cycling was performed at $0.7 \% \Delta \varepsilon$ and load control cycling was performed using stress limits defined by a $0.9 \% \Delta \varepsilon$ strain test. 


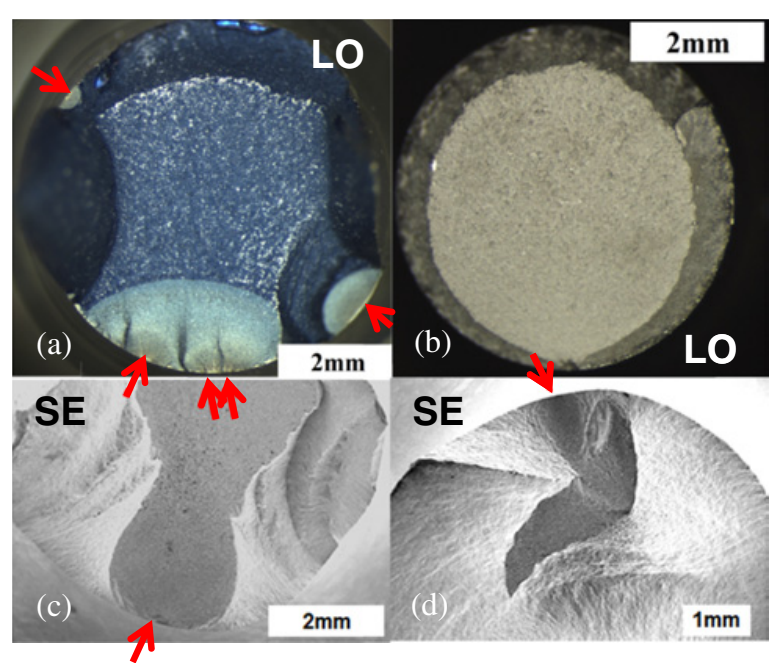

Figure 3. Examples of a typical (a) LC air minimum dwell, (b) SC subsurface baseline, (c) SC surface baseline and (d) LC vacuum minimum dwell fracture surface. LO - light optical, SE - secondary electron. Arrows indicate initiation sites.

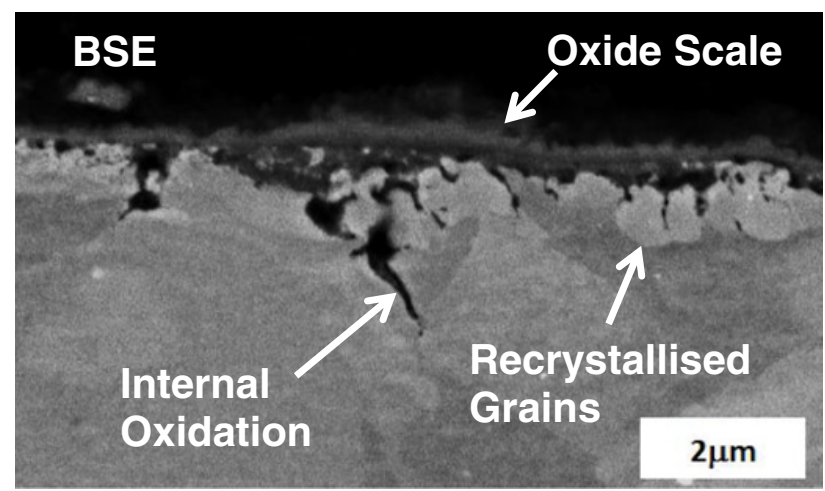

Figure 4. An example of the scale and internal oxidation damage found in minimum dwell test pieces (LC $0.9 \% \Delta \varepsilon \mathrm{Nf}=$ 8060 cycles $\sim 74$ hours at $650^{\circ} \mathrm{C}$ ).

Under strain control conditions, test results show more than an order of magnitude reduction in fatigue life for minimum dwell cycles compared to baseline fatigue cycles (Fig. 2a). However under load control conditions the difference between minimum dwell and baseline fatigue life was significantly reduced (Fig. 2b). Vacuum minimum dwell load control fatigue lives were approximately three times longer than air baseline lives.

Fracture surfaces indicate that minimum dwell fatigue increases the number of crack initiation sites compared to baseline cycling during load and strain control testing. At the same time a reduction in the total cycles to failure was measured under minimum dwell testing. A typical minimum dwell fracture surface showed multiple surface crack initiation sites with a heavily oxide tinted fracture surface. One air baseline test failed from a subsurface crack initiation site but the majority of air baseline tests failed from a single surface initiated site. Vacuum minimum dwell fracture surfaces also failed from a single crack initiation site. All surface cracks, under minimum dwell or baseline cycling, initiated in a transgranular mode before
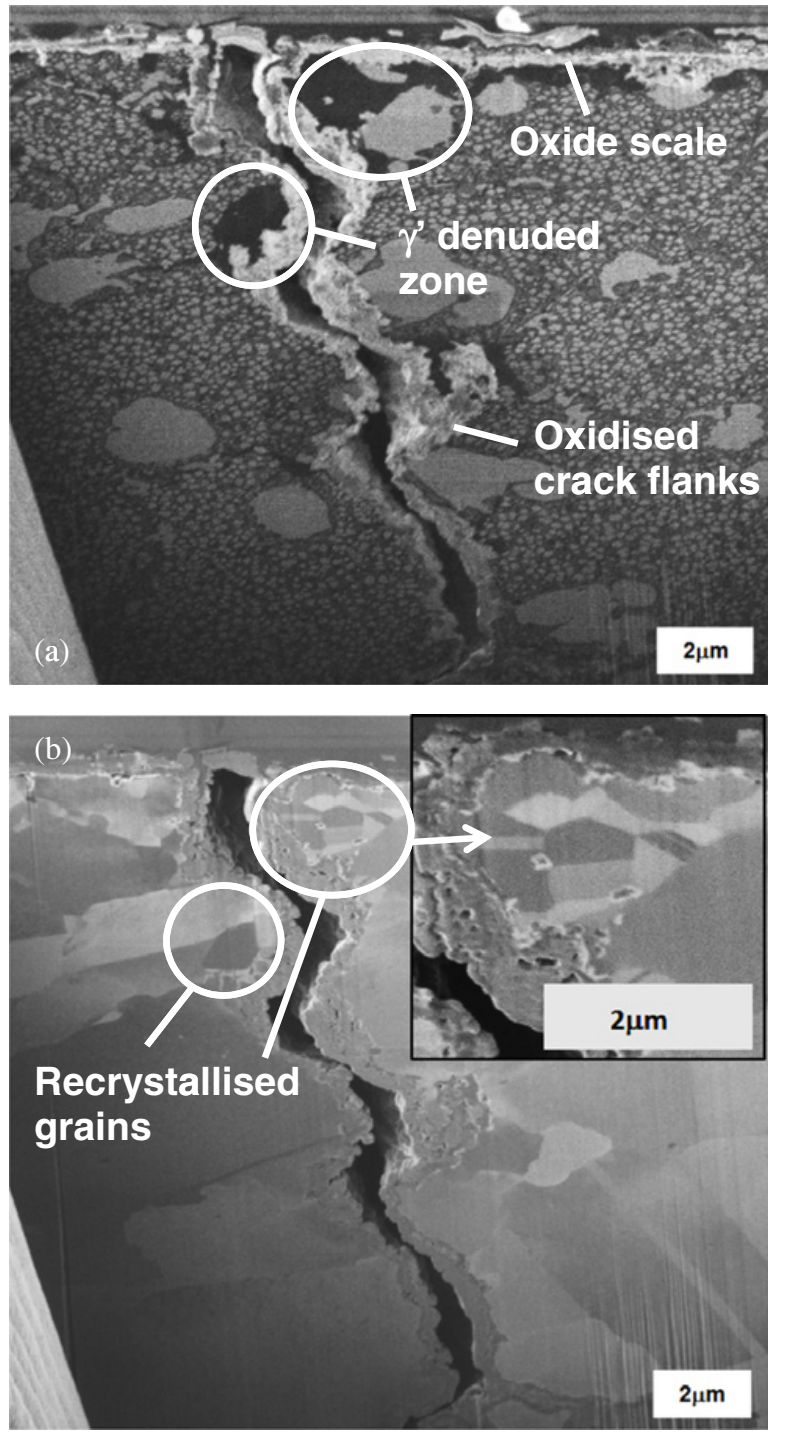

Figure 5. (a) Total positive ion (TPII) and (b) secondary electron (IISEI) images of a minimum dwell crack, where $\gamma^{\prime}$ denuded regions and (c) recrystallisation are found adjacent to the root of the crack. ( $\mathrm{SC} 0.7 \% \Delta \varepsilon, \mathrm{Nf}=5395$ cycles).

propagating in a mixed mode manner. This trend was found during load and strain control fatigue testing.

To determine the extent of the oxidation and internal damage, transverse metallographic sections of minimum dwell and baseline test pieces were prepared for FEG SEM analysis.

Under minimum dwell fatigue there appears to be a significant increase in the level of surface and subsurface oxidation at $650{ }^{\circ} \mathrm{C}$. Figure 4 shows the formation of a thick oxide scale at the surface with intergranular alumina fingers forming along boundaries of recrystallised grains. All minimum dwell test pieces exhibited oxidation damage of this type.

Focused ion beam (FIB) microscopy revealed more evidence of enhanced environmental interaction under minimum dwell fatigue. Sections of cracked and uncracked minimum dwell test pieces exhibited recrystallised $\gamma$ grains and denuded $\gamma^{\prime}$ regions adjacent to areas of surface oxidation and cracks (Fig. 5). 


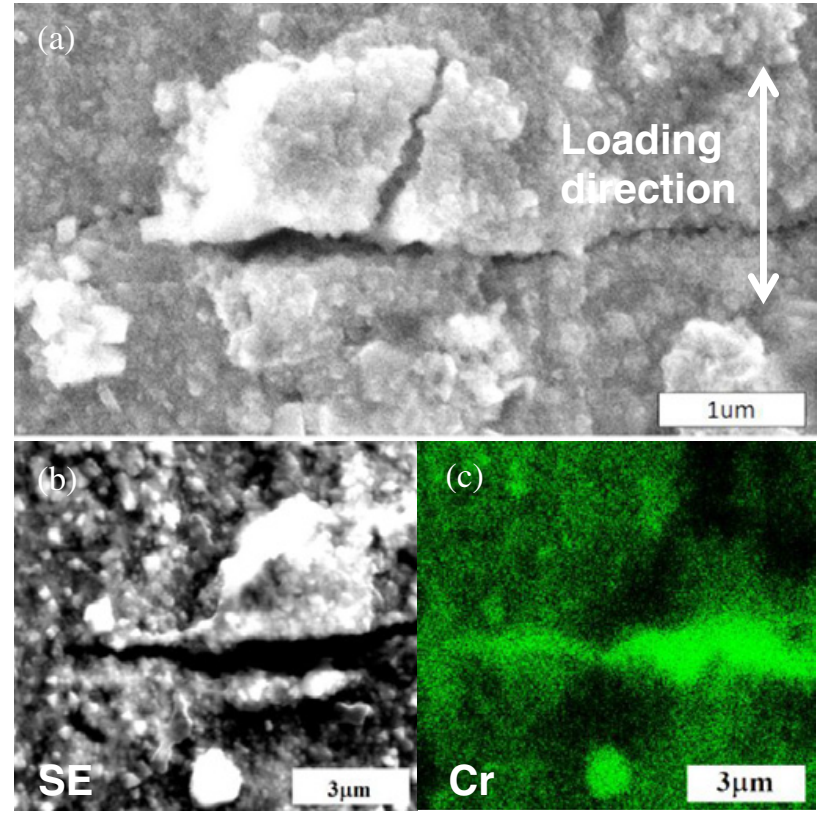

Figure 6. (a) Secondary electron image showing a typical oxide nodule found on a minimum dwell test piece with (b) and (c) showing chromium enrichment of minimum dwell fatigue crack (LC $0.9 \% \Delta \varepsilon, \mathrm{Nf}=2400$ cycles).

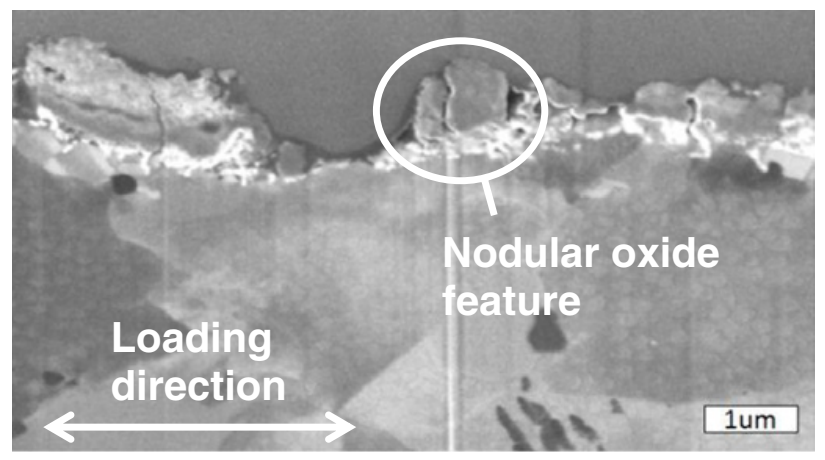

Figure 7. FIB TPII image of a cracked nodular oxide feature on a baseline test piece ( $\mathrm{SC} 0.7 \% \mathrm{De} \mathrm{Nf}=65341$ cycles).

Gauge length inspections of minimum dwell test pieces found a high volume of chromium and titanium rich fine grained $(\sim 0.2 \mu \mathrm{m})$ nodular oxides (Fig. 6). Cracks appear to initiate from these oxide nodules and propagate in a transgranular manner into the material. Cracks were then found to continue growing in a transgranular mode linking up with neighbouring cracks. Energy Dispersive Xray (EDX) mapping of minimum dwell cracks indicated chromia growth at cracked regions, a trend found in sectioned, FIB and at cracked nodular oxide features (Figs. 6b and c).

Polished sections of baseline test pieces exhibited virtually no significant oxidation damage, despite a similar amount of time spent under thermal exposure as per minimum dwell test pieces. However, an examination of the gauge length found large titanium rich nodular oxide features, larger than those found under minimum dwell fatigue and with a coarser oxide grain size $(\sim 0.4 \mu \mathrm{m})$.

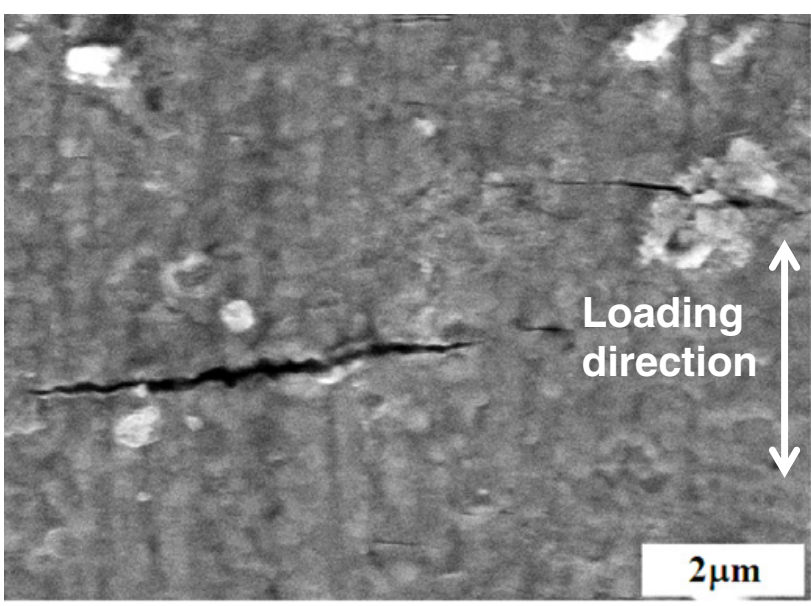

Figure 8. Secondary electron image of orthogonal cracking of nodular features found on the gauge length of vacuum minimum dwell test pieces ( $\mathrm{LC} 0.9 \% \Delta \varepsilon, \mathrm{Nf}=11019$ cycles).

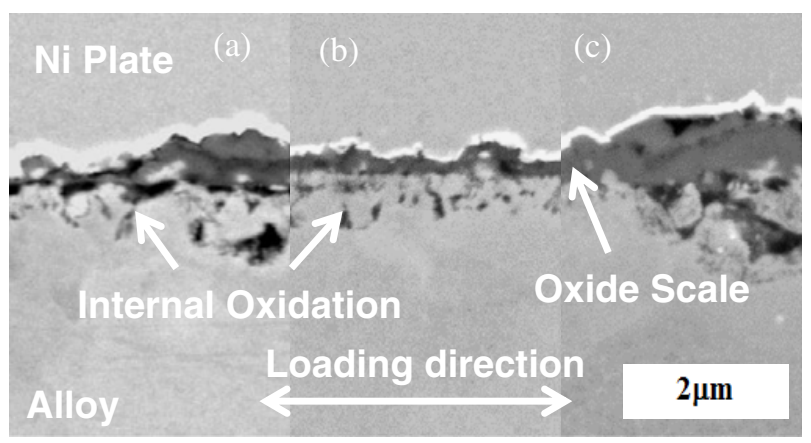

Figure 9. Backscatter electron images of oxidation damage after 200 hours at $700{ }^{\circ} \mathrm{C}$ under hold stresses of (a) $+600 \mathrm{MPa}$, (b) $0 \mathrm{MPa}$ and (c) $-600 \mathrm{MPa}$.

A large number of these oxide nodules appear to have cracked during testing but on closer inspection there appeared to be no propagation from the cracked nodule into the substrate (Fig. 7).

Despite limiting the oxidising environment, vacuum minimum dwell test pieces still exhibited cracked chromium rich oxide nodules on the test piece surface. (Fig. 8).

\subsection{Hold time oxidation}

Figure 9 shows the oxide scale formation under zeroapplied, tensile and compressive hold time stress, all after a 200 hour exposure at $700^{\circ} \mathrm{C}$. A continuous oxide scale formed under each stress condition. A significantly thinner oxide scale was formed at $650^{\circ} \mathrm{C}$ compared to $700^{\circ} \mathrm{C}$ with limited internal oxidation (Fig. 10). Exposures at $700{ }^{\circ} \mathrm{C}$ have shown significant internal oxidation and recrystallisation below the oxide scale. Compressive and tensile hold tests exhibited much thicker oxide intrusions compared to zero-applied stress tests.

Measurements of scale and internal damage (Fig. 10) indicate that a compressive hold stress increases the oxidation damage over tensile hold and zero stress furnace tests at $650{ }^{\circ} \mathrm{C}$ and $700{ }^{\circ} \mathrm{C}$. Tensile creep oxide scale and internal damage growth are significantly lower than 


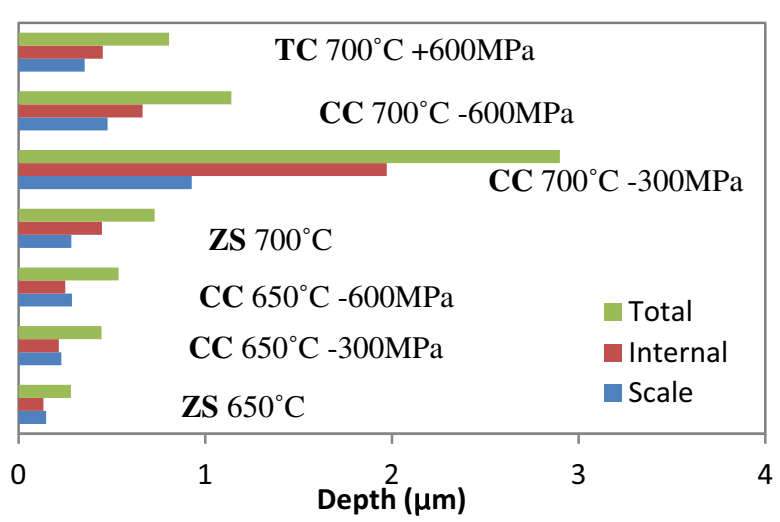

Figure 10. $650^{\circ} \mathrm{C}$ and $700^{\circ} \mathrm{C}$ oxide scale and internal damage measurements, where ZS - zero-applied stress, TC - tensile creep and $\mathrm{CC}$ - compressive creep.

those measured under similar compressive stress. A repeat test under a compressive hold at $700{ }^{\circ} \mathrm{C}$ and $-300 \mathrm{MPa}$ is required to confirm the significantly greater oxidation damage.

\section{Discussion}

Results from fatigue tests have shown a reduction in fatigue life when a minimum dwell period (1-1-1-30) is applied under load (using stress limits from a $0.9 \% \Delta \varepsilon$ trial) and strain $(0.7 \% \Delta \varepsilon)$ control conditions compared with baseline (1-1-1-1) fatigue at $650^{\circ} \mathrm{C}$. The major contributor to this reduction in life is thought to be the interaction of the environment during the dwell period.

Minimum dwell and baseline test pieces inspected via FIB on polished sections reveal a considerable increase in oxidation damage under minimum dwell fatigue. The current specimens received test exposures of $650{ }^{\circ} \mathrm{C}$ under minimum dwell fatigue for only 22 to 74 hours. Measurements from FIB analyses showed minimum dwell oxidation damage was of a similar magnitude to stress-free isothermal measurements quoted by Encinas-Oropesa et al after a more onerous 200 hour exposure at $700^{\circ} \mathrm{C}$ [5].

It seems plausible that the compressive hold during the minimum dwell period has led to enhanced oxidation damage, both surface and subsurface. The relatively fast accumulation of oxidation damage during the dwell period appears to crack when the scale is placed in tension following the ramp up from the dwell period. The cracked region reveals fresh material which is vulnerable to oxidation during the next dwell period. This process is then repeated until a micro-crack can nucleate across a grain in a transgranular manner.

Evidence of extensive oxidation damage around and, in some cases, ahead of the cracked region has been found during FIB studies of minimum dwell test pieces. Efforts to replicate this damage using compressive hold time oxidation has revealed a significant increase in oxidation damage over zero-applied stress oxidation at $650{ }^{\circ} \mathrm{C}$ and $700^{\circ} \mathrm{C}$. Back-to-back comparisons against tensile and zero-applied stress tests have found almost double the total oxidation damage under compression after 200 hours at $700{ }^{\circ} \mathrm{C}$ (Fig. 10). Zhou et al. found similar results for pure nickel oxidation at $700^{\circ} \mathrm{C}$. This increase in

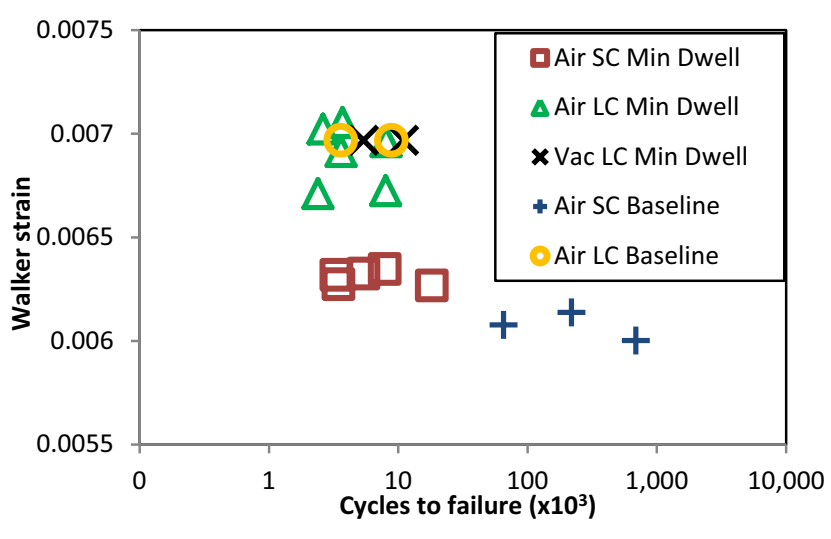

Figure 11. Walker strain plot of fatigue data produced in this study.

oxidation growth was attributed to the formation of a smaller oxide grain size, promoting short circuit grain boundary oxidation and scale growth $[6,7]$.

The surface residual stress of the polished test piece is also believed to influence the increased oxidation found during compression testing. X-ray diffraction (XRD) of minimum dwell test pieces has found a compressive residual stress of approximately $-380 \mathrm{MPa}$ at the surface from low stress grinding and polishing. It is believed that this residual stress increases the level of compressive stress that is applied during fatigue. In the case of the compressive hold test at $-600 \mathrm{MPa}$, the effective stress at the surface could be up to or greater than $-1000 \mathrm{MPa}$ whilst the tensile hold stress $(+600 \mathrm{MPa})$ would be reduced significantly. To confirm the effect of compression on the enhanced oxidation damage found in this research, repeat tests using residual stress-free test pieces are required.

The drop in fatigue life between minimum dwell and baseline fatigue was greater during strain control testing than under load control. The fatigue results produced in this research are plotted in Fig. 11 on a Walker strain versus endurance graph $(\mathrm{m} \approx 0.5)$ using Eq. (1).

$$
\Delta \varepsilon_{W}=\frac{\sigma_{\max }}{\varepsilon}\left(\left(\frac{\Delta_{\varepsilon} \varepsilon}{\sigma_{\max }}\right)^{m}\right) .
$$

In the strain control tests, as a result of stress relaxation, the magnitude of compressive stresses recorded at the end of the 30 second dwell period at zero strain were lower compared to those from the baseline 1 second dwell. When test pieces were then cycled to maximum strain, greater peak stresses were produced compared to those from baseline strain fatigue, by $\sim 70 \mathrm{MPa}$ (see Fig. 12).

It is proposed that this difference in peak stress has caused the large reduction in fatigue life between strain control minimum dwell and baseline fatigue. This would also rationalise the much smaller reduction in life between load control minimum dwell and baseline fatigue, since peak stress levels would be similar for both tests. The peak stress effect can be seen by the separation of strain controlled minimum dwell fatigue data from the rest of the data in Fig. 11. 


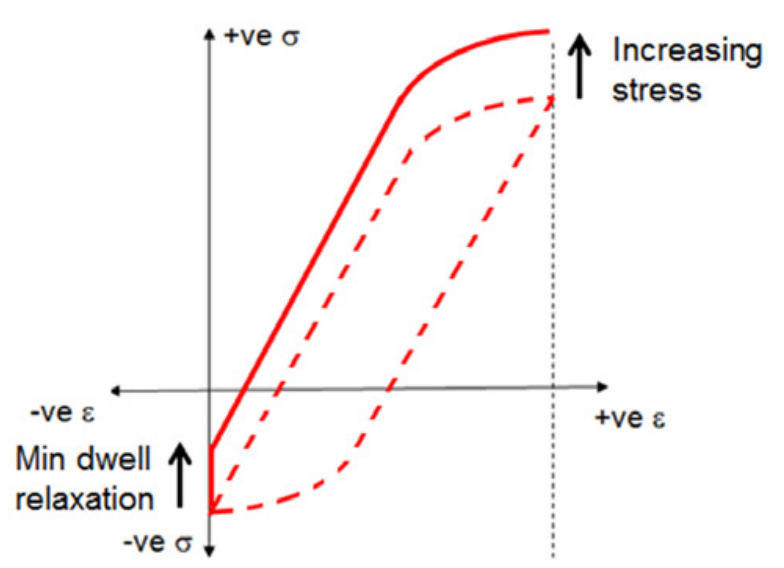

Figure 12. A schematic of the stress relaxation that occurs during the minimum dwell period, and its effect on the peak maximum stress.

\section{Conclusions}

A programme of minimum dwell fatigue (1-1-1-30) testing under an air and vacuum environment has been performed on RR1000 alongside baseline fatigue tests (1-1-1-1) at $650{ }^{\circ} \mathrm{C}$. To determine the enhanced environmental interaction under the dwell cycle, thermal exposure under sustained compressive loading was performed at stress levels of $-300 \mathrm{MPa}$ and $-600 \mathrm{MPa}$ and at temperatures of $650{ }^{\circ} \mathrm{C}$ and $700{ }^{\circ} \mathrm{C}$. The results of these test programmes show that:

- Minimum dwell fatigue causes more than an order of magnitude reduction in fatigue life under strain control conditions $(0.7 \% \Delta \varepsilon)$ compared to that under baseline cycles. A smaller life reduction was found under load control conditions $(0.9 \% \Delta \varepsilon$ stress limits).

- The reduced fatigue life under air minimum dwell fatigue is thought to be caused by early crack initiation as a result of enhanced oxidation damage during the compressive dwell period.
- Compressive hold times were found to increase oxidation damage at $650{ }^{\circ} \mathrm{C}$ and $700{ }^{\circ} \mathrm{C}$ compared to tensile and zero-applied stress tests.

- Peak tensile stress levels were increased under strain control minimum dwell conditions due to relaxation of compressive stresses during the dwell period at minimum strain, the result of which is likely to have caused greater than an order magnitude reduction in fatigue life over baseline cycling.

- Vacuum minimum dwell fatigue improves fatigue life over air baseline fatigue under load control.

The current research was funded by the EPSRC RollsRoyce Strategic Partnership in Structural Metallic Systems for Gas Turbines (grants EP/H500383/1and EP/H022309/1). The provision of materials and technical support from Rolls-Royce plc is gratefully acknowledged. The authors would like to thank staff at SMaRT (Colin Small, Mark Griffiths and Tom Griffiths), Dr Mark Whittaker, Dr Paul Jones, Jonathan Jones and Christopher Newton at Swansea University; Dr Barbara Shollock at Imperial College, London; and Gary Harrison at Manchester University.

\section{References}

[1] M.R. Bache, J.P. Jones, G.L. Drew, M.C. Hardy, N. Fox, Int. Jour. Fat. V 31, 1719 (2009)

[2] T.P. Gabb, J. Telesman, P.T. Kantzos, J.W. Smith, P.F. Browning, Superalloys 2004, 269 (2004)

[3] J. Telesman, T.P. Gabb, Y. Yamada, L.J. Ghosn, D. Hornbach, N. Jayaraman, Superalloys 2012, 853 (2012)

[4] R.J. Mitchell, M.C. Hardy, M. Preuss, S. Tin, Superalloys 2004, 361 (2004)

[5] A. Encinas-Oropesa, G.L. Drew, M.C. Hardy, A.J. Leggett, J.R. Nicholls, N.J. Simms, Superalloys 2008, 609 (2008)

[6] C.H. Zhou, H.T. Ma, L. Wang, Corrosion Science 52 210 (2010)

[7] G. Moulin, P. Arevalo, A. Salleo, Oxidation of Metals 45, 153 (1996) 